\title{
Dança no ensino médio: experiência com o uso das Tics
}

\section{RESUMO}

O objetivo desse artigo foi avaliar uma experiência com a dança no Ensino Médio utilizando as Tecnologias da Informação e Comunicação (TICs) como recurso pedagógico. Assim, produzimos um material didático para o professor pautado nas orientações da Base Nacional Comum Curricular (Segunda versão) e posteriormente, desenvolvemos experiências didáticas nas aulas. Os resultados apontaram maior reconhecimento da dança enquanto um conteúdo regular da Educação Física, além de um impacto positivo na aprendizagem e na motivação dos alunos com a inserção das tecnologias.

PALAVRAS-CHAVE: Educação física escolar; Dança; Ensino médio; TICs

\section{Irlla Karla dos Santos Diniz}

Doutorado em Desenvolvimento Humano e Tecnologias Instituto Federal de Educação, Ciência e Tecnologia de São Paulo, Capivari, Brasil irllakarla@yahoo.com ○ https://orcid.org/0000-0003-2520-1514

Suraya Cristina Darido Doutorado em Psicologia Escolar e Desenvolvimento Humano

Universidade Estadual Paulista Júlio de Mesquita Filho, Departamento de Educação

Física, Rio Claro, Brasil. surayacd@rc.unesp.br ○ https://orcid.org/0000-0001-9491-1291 


\title{
Dance in high school: experience with ICTs use
}

\begin{abstract}
This paper aimed to evaluate an experience with dance in high school using Information and Communication Technologies (ICTs) as a pedagogical resource. It was produced a teaching material for teachers based on the orientations of The National Common Curricular Base (second version) and subsequently it was developed didactic experiences in classes. The results showed greater recognition of dance as a regular content of Physical Education, as well as positive impact in students' learning and motivation with the insertion of technologies.
\end{abstract}

KEYWORDS: School physical education; Dance; High school; ICTs

\section{Danza en la escuela secundaria: experiencia con el uso de las TICs}

\section{RESUMEN}

El objetivo de este artículo fue evaluar una experiencia con la danza en la escuela secundaria utilizando las Tecnologías de la Información y la Comunicación (TICs) como recurso pedagógico. Así, produjimos un material de enseñanza para el maestro basado en las orientaciones de la Base Curricular Nacional Común (Segunda versión) y más tarde, desarrollamos experiencias didácticas en las clases. Los resultados indicaron un mayor reconocimiento de la danza como un contenido regular de Educación Física, así como un impacto positivo en el aprendizaje y la motivación de los estudiantes con la inserción de tecnologías

PALABRAS-CLAVE: Educación física escolar; Danza; Escuela secundaria; TICs 


\section{INTRODUÇÃO}

Pensar $^{1}$ sobre o espaço que a dança, enquanto um dos conteúdos da cultura corporal, possui na escola, é lidar com a ausência de práticas e de experiências acumuladas ao longo da história. Sabemos que ela enfrenta diversas barreiras para se consolidar como um conhecimento regular nas aulas (BRASILEIRO, 2009; SANTOSO; FREITAS, 2010; DINIZ; DARIDO, 2015), e com isso, frequentemente é questionada enquanto um saber da Educação Física (EF).

Não é raro nós professores ouvirmos frases como: "Não sou boa com esportes, por isso não gosto de Educação Física" ou ainda "Sempre sou escolhido por último, e assim, não me sinto motivado para as aulas", entre tantas outras que demarcam o quanto essa disciplina ainda privilegia práticas esportivas e os considerados mais habilidosos, tornando "invisíveis" aqueles que não se encaixam nesse padrão.

Podemos dizer que as experiências pedagógicas com dança no Ensino Médio (EM) são ainda mais limitadas (BRASILEIRO, 2002-2003; SCARPATO, 2004; DINIZ; DARIDO, 2019) devido às dispensas, expectativa do vestibular, oferecimento das aulas no contra turno, entre tantos outros problemas. Agrega-se a esse cenário, o fato de que continuamos investindo em pesquisas no Ensino Fundamental, ou mesmo privilegiando práticas corporais mais consolidadas. É necessário valorizar experiências pedagógicas no Ensino Médio e aproximar os professores dessas possibilidades, buscando maior valorização da Educação Física nessa etapa de ensino. Sabemos que o EM ainda possui questões relacionadas à sua legitimidade, ao processo recente de reformas curriculares e até mesmo sobre qual o seu real papel na educação básica, o que reforça a necessidade de pesquisas, experiências e debates sobre ele.

Para além das dificuldades que a EF e o próprio EM já enfrentam, acrescentamos às nossas reflexões a revolução tecnológica iniciada nas últimas décadas (CASTELLS, 1999), que colocaram os aplicativos, as redes sociais, os smartphones e jogos digitais como elementos mais presentes na vida dos estudantes. Tal constatação, tem levantado um debate sobre como a escola pode lidar com esse novo contexto. Há vinte anos, Betti (2001) já sinalizava para o uso das mídias como aliadas ao processo de aprendizagem e para a necessidade de superar sua "demonização", tema que agora, ganha ainda mais notoriedade.

\footnotetext{
${ }^{1}$ Esse artigo apresenta parte dos resultados da pesquisa de doutorado da primeira autora..
} 
Destacaremos em especial, as Tecnologias da Informação e Comunicação (TICs) como foco dessa pesquisa, que segundo Kenski (2010) tratam-se de ferramentas que aliam as linguagens oral, escrita, sonora, da imagem e do gesto, traduzidas em veículos analógicos ou digitais, ou seja, englobam desde o jornal e o rádio, até as redes sociais, os celulares e a internet. Alguns estudos no campo da EF já têm procurado explorar o potencial dessas ferramentas (FERREIRA, 2014; MILANI, 2015; GERMANO, 2015), diversificando as estratégias didáticas e incluindo-as no processo educativo daqueles denominados nativos digitais (PRENSKI, 2001), pois já nasceram numa sociedade digitalizada.

No bojo dessas questões, a proposta de incluir as TICs na produção de um material didático ${ }^{2}$ de dança, justifica-se pela compreensão de que o processo educativo não pode mais ser o mesmo diante do significado que as tecnologias possuem na contemporaneidade. A escola é uma instituição republicana que possui como um de seus princípios inserir os alunos na cultura, tratando os conhecimentos de forma crítica e autônoma (GONZÁLEZ; FENSTERSEIFER, 2009). Para tanto, um de seus papéis seria integrar os alunos na sociedade digital, considerando a grande interferência dessas tecnologias nos campos sociais.

Nesse âmbito, a partir da compreensão de que precisamos de experiências, materiais didáticos e pesquisas que possam auxiliar no trato da dança na escola, temos como objetivo avaliar uma experiência com a dança no Ensino Médio, utilizando às Tecnologias da Informação e Comunicação (TICs) como recurso pedagógico.

\section{MÉTODO}

Este estudo possui natureza qualitativa, ou seja, teve como finalidade diagnosticar, analisar e descrever fenômenos sociais (MAANEN, 1979). De modo específico, desenvolvemos uma pesquisa-ação (ELLIOT, 1993; THIOLLENT, 1994; TRIPP, 2005) que propôs a resolução de um problema coletivo, de forma que o pesquisador e os participantes atuaram diretamente na situação investigada (THIOLLENT, 1994). Para tanto, partimos do pouco espaço que a dança possui na escola, para implementar uma ação interventiva com o apoio das TICs no EM. Como acentua Perrenoud (1997, p. 35) "a investigação-ação é uma via de transformação dos laços entre a investigação e o ensino, através do confronto direto das respectivas práticas num mesmo terreno".

\footnotetext{
${ }^{2} \mathrm{O}$ material didático produzido está disponível na tese da primeira autora.
} 
Inicialmente produzimos um material didático voltado ao EM, baseado em análises documentais das Propostas Curriculares Estaduais (21 documentos ${ }^{3}$ ), da Base Nacional Comum Curricular (BNCC) Segunda Versão ${ }^{4}$ (BRASIL, 2016) e nas experiências pedagógicas das autoras. O objetivo do material foi propor o ensino da dança no Ensino Médio empregando as TICs como recurso didático.

Num segundo momento, iniciamos a investigação-ação que envolveu o planejamento coletivo na escola (antes do início do ano letivo de 2015), as reuniões ordinárias semanais (preparação do projeto), sábados letivos, o evento de encerramento e aulas regulares. Todas as discussões construídas durante os encontros pedagógicos foram devidamente registradas no diário de campo e deram suporte para o planejamento e desenvolvimento das vivências.

Implementamos oito aulas com quatro turmas mistas do $1^{\circ}$ ano do Ensino Médio de um campus do interior paulista do Instituto Federal de Educação, Ciência e Tecnologias de São Paulo IFSP, a partir do material didático elaborado. As turmas possuíam 20 alunos com idade média de 14 anos. Designamos os grupos da seguinte maneira: Informática A, Informática B, Química A e Química B, em referência ao curso técnico que cursavam. Todas tiveram quatro aulas duplas de dança (100 minutos de duração cada). Houve ainda, um sábado letivo em que foram desenvolvidas atividades interdisciplinares sobre o tema abordado, além do evento final que contou com a presença da comunidade externa.

Para a fase de avaliação junto aos estudantes, utilizamos a técnica de grupo focal (GATTI, 2005). Para Minayo (2000) o grupo focal (GF) proporciona uma análise multifacetada sobre o objeto investigado. Antes de iniciar a implementação, fizemos um encontro-diagnóstico para mapear como eram as experiências anteriores dos alunos com a EF e com a dança na escola, e por fim, uma reunião de avaliação. Para compor o GF foram sorteados oito alunos, sendo dois de cada turma e um de cada sexo, totalizando quatro meninos e quatro meninas. Os estudantes foram

\footnotetext{
${ }^{3}$ Analisamos os documentos que estavam disponíveis nos sites das secretarias de educação de cada estado. Sendo eles: Acre (2010), Alagoas (2014), Amapá (2009), Amazonas (2012), Ceará (2008), Distrito Federal (2013), Espírito Santo (2009), Goiás (2009), Maranhão (2015), Mato Grosso (2010), Mato Grosso do Sul (2012), Minas Gerais (2009), Paraná (2008), Pernambuco (2013), Piauí (2013) Rio de Janeiro (2013), Rio Grande do Sul (2009), Rondônia (2013), São Paulo (2012), Sergipe (2010), Tocantins (2010). Os resultados dessa pesquisa estão publicados no artigo Análise do conteúdo dança nas Propostas Curriculares Estaduais de Educação Física do Brasil, publicado na Revista da Educação Física (UEM. Online).

${ }^{4}$ Iniciamos essa pesquisa com a Segunda Versão da BNCC (BRASIL, 2016), todavia, ao longo do processo de investigação o documento foi modificado. Como o material didático já havia sido elaborado e nossos objetivos estavam associados ao ensino da dança mediado pelas TICs, mantivemos nosso cronograma por acreditar que isso não traria interferências.
} 
numerados de acordo com a ordem em que as aulas foram ministradas nas turmas ( 1 a 8 ) recebendo a designação por sexo (aluno/aluna) para preservar suas identidades.

Empregamos também como técnicas de coleta de dados a observação participante (GIL,1999) e o diário de campo (THOMAS; NELSON; SILVERMAN; 2007). Desse modo, muitos dados como as sensações, dúvidas e comentários foram considerados no processo investigativo. Uma vez que adotamos as redes sociais (facebook, instagram e whatsapp) como recursos didáticos, os comentários deixados nesses espaços também foram incluídos no diário de campo (DC), e, consequentemente, nas análises. Desse modo, quando os registros apareceram nas redes sociais utilizamos designações por letras (A, B, C, etc.), para caracterizar os alunos de forma diferente dos trechos obtidos durante as reuniões do grupo focal (GF).

Por fim, assinalamos que a presente pesquisa foi aprovada pelo Comitê de Ética em Pesquisa do Instituto de Biociências - UNESP Rio Claro por meio do parecer 1.210.309. O TCLE (Termo de Consentimento Livre e Esclarecido) foi encaminhado aos responsáveis legais para autorização, e os próprios alunos também assinaram o Termo do Assentimento, uma versão simplificada do documento.

\subsection{Caracterização da Amostra}

A pesquisa foi desenvolvida no Instituto Federal de Educação, Ciência e Tecnologia de São Paulo - IFSP, num campus do interior paulista. A instituição oferece duas modalidades de cursos integrados ao EM, o Técnico Integrado em Química (40 vagas) e o Técnico Integrado em Informática (40 vagas). Os alunos cursam três anos em horário integral (das $08 \mathrm{~h}$ às $17 \mathrm{~h}$ ), e no período em que o estudo foi realizado ( $1^{\circ}$ semestre de 2015$)$ havia uma seleção por meio de vestibular, com $50 \%$ das vagas reservadas para cotas sociais e raciais.

A infraestrutura da escola é limitada, de forma que os espaços de convivência, salas de aula ou laboratórios não são insuficientes, além disso, as aulas de EF são realizadas em ambientes adaptados como pátio, gramado e estacionamento. Em alguns dias, por meio de uma parceria com a prefeitura da cidade, as aulas acontecem no ginásio municipal, o que possibilita melhores condições estruturais.

\subsection{Caracterização do Percurso}

As danças propostas no material didático foram definidas nas reuniões de planejamento do projeto interdisciplinar da escola. Tivemos dois encontros antes do início do ano letivo de 2015 e 
depois o tema foi retomado nas reuniões ordinárias com a presença dos professores (aproximadamente 13 em cada curso e apenas 1 de EF), coordenadores e pedagogos. Por parte das pesquisadoras, procuramos associar o projeto da escola às indicações da BNCC (BRASIL, 2016) que previa para o EM ações coletivas. Todas as reuniões foram registradas no diário de campo, a fim de produzir dados sobre o processo de planejamento e construção da pesquisa.

Um dos objetivos da equipe escolar era elaborar um projeto interdisciplinar que promovesse maior aproximação entre as áreas do conhecimento (Linguagens, Ciências Humanas, Ciências da Natureza, Matemática e as Áreas técnicas - Química e Informática), e os saberes que seriam abordados no $1^{\mathrm{o}}$ semestre de 2015 , procurando também, minimizar a sobrecarga gerada pela educação em tempo integral. Os cursos faziam reuniões separadas e também algumas conjuntas que auxiliaram na articulação das ações.

Após alguns debates, o tema escolhido pelo grupo de professores para o $1^{\mathrm{o}}$ ano do EM foi "Cultura e Identidades locais", com o objetivo de associar os conteúdos de cada disciplina com os saberes tradicionais/populares da cidade. Diante disso, cada docente pôde inicialmente planejar algumas possibilidades de intervenção, e, num segundo momento, definir a sua proposta, o que foi acontecendo por meio de discussões nas próprias reuniões.

A Educação Física propôs a abordagem das danças populares que se manifestavam na região de investigação, juntamente com contribuições de outras disciplinas como Sociologia, Artes e Português. Entendemos que as danças populares, devido sua riqueza histórica e social, estão diretamente relacionadas com as identidades de um povo, isto é, seus significados, gestos, valores e formas de comunicação (NANNI,1995). Dessa forma, elas seriam ideais enquanto indicação da EF, uma vez que além de ser uma das práticas mais indicadas pelas Propostas Curriculares no campo da dança (DINIZ; DARIDO, 2015) proporcionaria diálogos interdisciplinares significativos para o projeto.

Devido a especificidade do estudo, daremos enfoque nesse artigo às ações desenvolvidas pela disciplina de EF, e, em particular, sobre as experiências com as danças populares e as tecnologias, uma vez que se trata de um recorte do que foi produzido por vários componentes curriculares no projeto coletivo da escola.

Durante as reuniões que aconteciam semanalmente, trouxemos alguns levantamentos sobre grupos culturais locais, além de sugestões dos alunos e dos demais professores para definir quais danças seriam abordadas. Com isso, deliberamos por: batuque de umbigada, samba de lenço, cirandas (rodas cantadas) e maculelê. O batuque é uma prática bastante reconhecida na cidade pela 
existência de um grupo folclórico (Guaiás de Capivari), e assim, sua indicação foi unanimidade. As brincadeiras cantadas foram propostas pelos docentes de outras disciplinas, pela relação com o universo da infância e da necessidade de recuperar experiências deixadas no passado. Com isso, sugerimos iniciar com as brincadeiras cantadas e encaminhar para as cirandas paulistas, com o objetivo de ampliar a concepção dos alunos sobre as danças em roda. O maculelê e o samba de lenço foram elencados principalmente pela origem africana e pelos significados que possuíam para a região.

A meta foi que cada turma se aprofundasse em uma manifestação, mas sem deixar de conhecer as quatro selecionadas, de forma que tivemos a seguinte disposição definida por sorteio: Informática A: Samba de lenço, Informática B: Batuque de umbigada, Química A: Ciranda e Química B: Maculelê. Num segundo momento, iniciamos o planejamento sobre os recursos tecnológicos que seriam empregados no projeto, e assim, definimos como principais ferramentas as redes sociais pelo relacionamento próximo e significativo que os estudantes mantinham com elas. Desse modo, programamos atividades de pesquisa, registro, interação e produção de conteúdos utilizando o facebook, o instagram e o whatsapp.

Como forma de encerramento do projeto da escola "Cultura e Identidades locais", os professores decidiram que os alunos apresentariam os trabalhos na festa de encerramento do semestre. Assim, cada docente teve que refletir sobre alguns "produtos" que seriam expostos nessa etapa, e a EF assumiu o desafio de trazer composições de dança com cada uma das turmas.

\subsection{Análise dos dados}

Para essa etapa desenvolvemos uma análise qualitativa descritiva, método que depende da capacidade analítica do pesquisador e que prevê ampla seleção e posterior sintetização e inferências sobre as informações coletadas (GIL, 2008). Segundo o autor, a análise descritiva se constitui em uma técnica adequada para investigações como a pesquisa-ação e a análise documental, vertentes que adotamos no presente estudo. Procuramos construir um rigoroso processo descritivo que foi sistemático e cíclico, dialogando os resultados com os objetivos principais da investigação. Respeitando essa diretriz, estabelecemos as categorias que foram organizadas a partir de um manejo qualitativo interpretativo.

\section{RESULTADOS}




\subsection{Dança no Ensino Médio}

\section{Como as aulas foram organizadas?}

Inicialmente, descreveremos como o método de ensino foi organizado na pesquisa, e as impressões obtidas principalmente por meio dos registros no diário de campo (DC). Esses dados auxiliaram a compreender o desenvolvimento das aulas e os principais impactos de nossa experiência didática. Organizamos as aulas em cinco etapas: roda inicial, exploração, solução de problemas, direcionamento e roda final, o que foi definido a partir de investigações na literatura e das experiências pedagógicas das autoras.

A roda inicial, já utilizada em outras pesquisas (DARIDO; RANGEL, 2005; DARIDO; SOUZA JÚNIOR, 2007; DARIDO, 2011; DARIDO, 2012), trata-se de uma estratégia que permite maior envolvimento dos estudantes. Esse espaço se configurou em um dos momentos mais intensos de mobilização e trocas de saberes, ratificando sua relevância. Scarpato (2001) também observou em seu estudo com dança educativa, a importância das rodas de conversas no início das aulas, pois nelas havia um rico compartilhamento de experiências.

Já na segunda etapa (exploração), a meta foi viabilizar aos discentes, contato direto com as danças. Nessa fase, lidamos com as maiores dificuldades uma vez que os alunos não estavam acostumados com aulas menos diretivas. Isto é, quando foram desafiados a experimentar com liberdade, sentiram-se um pouco desconfortáveis. Schiavon (2003) aponta que no método dos três momentos aplicado ao ensino da ginástica, a fase de exploração é justamente uma das mais complexas, o que acontece pela ausência de experiências anteriores com as práticas corporais ou mesmo pela necessidade de criar e não apenas reproduzir. Entretanto, aos poucos os alunos foram se acostumando com o método e construindo a cada aula, movimentos em conjunto.

$\mathrm{Na}$ fase de solução de problemas, procuramos instigar os alunos por meio de atividades que exigiam uma aproximação ainda maior com os conteúdos. Para tanto, eles foram desafiados individual e coletivamente por meio de "situações-problema", em que precisavam apresentar respostas que ampliassem os significados dos saberes. O enfoque ao explorar essa estratégia foi colocar o aluno em uma posição crítica durante as atividades (MASETTO, 2010) o que inverte a lógica tradicional de ensino. De acordo com Pozo e Echeverría (1998) a proposição de situações-problema coloca o educando em função ativa, ou pelo menos diante de um esforço para buscar respostas em seu próprio conhecimento. Com isso, eles se tornaram mais capazes para dominar os procedimentos, conceitos e atitudes. 
$\mathrm{Na}$ quarta fase do método, denominada de direcionamento, a proposta foi justamente imprimir atividades baseadas nas instruções docentes. Procuramos no projeto, dar maior ênfase às etapas anteriores (exploração e solução de problemas), primeiro por acreditar que momentos diretivos já são tradicionalmente predominantes na educação, e depois, por conceber que a participação ativa dos estudantes seria mais significativa para a formação deles.

Gozzi e Ruete (2006) ao desenvolver uma pesquisa com estilos de ensino na Educação Física, constataram que principalmente com as atividades motoras, os alunos vão ganhando autonomia com o tempo, e assim, vão deixando de ser tão dependentes do professor, o que também identificamos ao longo dessa investigação.

$\mathrm{Na}$ roda final, procuramos recuperar os saberes mobilizados ao longo das aulas e confrontar as expectativas e dificuldades enfrentadas em cada fase. O objetivo foi retomar os conteúdos, ouvir as sensações e progressos dos alunos, sinalizando que não há linearidade no processo de ensino e aprendizagem e que, juntos, poderíamos evoluir a cada aula.

No geral, podemos dizer que apesar de desafiador, o método de ensino adotado pôde transformar a experiência com a dança na escola, pois os alunos foram protagonistas da própria aprendizagem. Todavia, a experiência foi bastante desafiadora, uma vez que tratava-se de um novo formato de aula de EF, com um conteúdo pouco vivenciado por eles e que já trazia alguns estigmas sociais. Além disso, havia ainda a presença das tecnologias, o que fez que os alunos demorassem algumas aulas até se adaptarem ao projeto.

\section{Para além do dançar: o que aprendi?}

Inicialmente, os alunos ficaram bastante surpresos com a proposta da EF como um todo, primeiro porque suas experiências anteriores eram baseadas no "rola a bola", e depois porque a dança praticamente não fazia parte das aulas dessa disciplina. Sobre as experiências que antecederam o ingresso no IFSP, eles afirmaram:

\footnotetext{
"Basicamente todos os anos que eu fiquei naquela escola eu só joguei queimada! [...] Ela seguia o cronograma da apostila [...]. Ela dava uma aula com toda a matéria que tinha na apostila e depois a gente só ficava jogando queimada. Dividia a quadra, as meninas jogavam queimada e os meninos jogavam futsal" (Informação verbal - GF - Aluna 6).

"Em relação à dança nunca tive e nem ouvia falar o que era dança na escola" (Informação verbal - GF- Aluno 8).
}

\footnotetext{
5 "Rola a bola" é uma expressão utilizada para designar aulas de Educação Física em que o professor distribui os materiais, em especial a bola, e permite que os alunos joguem sem nenhuma (ou pouca) intervenção pedagógica.
} 
"Dança era só um grupinho de meninas que se organizavam e faziam, não tinham interação com as outras, só era elas que faziam. E se outras pessoas quisessem dançar não podia, parecia. E aí tinha apresentação quando tinha evento, sabe?" (Informação verbal - GF- Aluna 3).

Os relatos ratificaram a ausência da dança na escola, evidenciando a proximidade com as apresentações nas festas tradicionais e o pouco vínculo com as aulas regulares, dados já identificados em outros estudos (SBORQUIA; GALLARDO, 2002; EHRENBERG, 2003; BRASILEIRO, 2009; DINIZ, 2014). Tal cenário suscitou a necessidade de explorar o reconhecimento da dança como um dos conhecimentos que precisam ser legitimados no currículo da EF.

O "rola-bola", apesar de sofrer críticas inclusive dos alunos (SILVEIRA; PINTO, 2001) é celebrado por uma parte, uma vez que eles tomam decisões sobre o que vão ou não fazer nas aulas, e assim, sentem-se confortáveis em contestar alguns conteúdos. Todavia, apesar do estranhamento inicial, procuramos construir novos significados para EF durante as aulas, fortalecendo o conceito de cultura corporal e possibilitando novas experiências.

É preciso frisar também que, para alguns ainda foi bastante intimidador dançar na escola (vergonha, falta de experiências, questões culturais, entre outros), o que se constituiu como um fator limitante do estudo, reforçando a necessidade de vivências contínuas para minimizar tais impactos. Para tanto, aos poucos procuramos auxiliar os alunos a ultrapassarem essas e outras barreiras, e assim, aproveitarem ao máximo as oportunidades de contato com a dança. Com isso, no decorrer da pesquisa foi possível presenciar o "boleiro" girando na ciranda, a menina que pouco participava das aulas se desafiando nas batidas de maculelê, ou mesmo aquele aluno tímido, sorrindo enquanto coordenava alguns passos com o lenço.

Ademais, a dança foi explorada para além das dimensões práticas, o que também contribuiu para a ressignificação do espaço de aprendizagem. Tematizar um saber nas aulas de EF é justamente fomentar conhecimentos conceituais, atitudinais e procedimentais (COLL, et al., 2000), de forma que esse processo gerou novas compreensões:

[...] primeiramente eu achei que ia ser danças que tava no auge, que fazia mais os nossos gostos e estilos, mais depois que você mostrou esses novos tipos de dança que faz parte da nossa cultura e nós nem sabíamos, primeiramente eu achei: nossa o que é isso? Mas depois que você passou todo o conteúdo e expôs o conteúdo histórico foi demais. E respondendo a sua pergunta, sim, foi muito legal pois resgatou coisas da nossa cultura. Sim, eu acho batuque de umbigada legal (Relato via whatsapp - DC - Aluno C).

\footnotetext{
${ }^{6}$ Aluno que normalmente se identifica com o futebol e tem resistência a outros conteúdos da cultura corporal nas aulas de Educação Física.
} 
Para os estudantes, aprender sobre as danças populares e o significado dessas manifestações na construção da identidade foi uma experiência transformadora. Isso aconteceu, pois as discussões versaram sobre a história, o contexto de surgimento das manifestações, suas construções sociais na comunidade, além das experiências pessoais dos próprios alunos.

“Ah... com certeza ter aprendido a cultura! Foi muito legal saber que por trás de todo um povo que eu já conhecia [...], eu não sabia que tinha todas essas culturas... essas danças. E foi muito interessante saber o significado delas, as histórias também por trás delas" (Informação verbal - GF - Aluna 7).

"Acho que o mais importante... assim da aula não é aprender a dança em si, mas o que tá assim por trás dela. A luta, a resistência pela cultura. Por exemplo, contra aqueles que tentaram acabar com o batuque. [...] A história foi muito importante" (Informação verbal - GF - Aluno 5).

Ficou evidente como o tratamento da dança em uma perspectiva para além dos gestos e coreografias acabou sendo um dos pontos mais lembrados por eles nas discussões, seja no grupo focal, nas aulas ou mesmo nos ambientes virtuais. Eles entenderam que na EF também há conceitos, valores e reflexões que são importantes para uma formação crítica e significativa.

Ao compreendermos a dança como parte da identidade cultural, fortalecemos um debate sobre os impactos de diversos eventos sociais e culturais relacionados ao batuque de umbigada, ao samba de lenço, ao maculelê e às cirandas. Ou seja, sobre a ligação que há entre a sociedade e a dança, e o seu reconhecimento enquanto grupo (GARAUDY, 1980).

[...] As aulas e dança foram algo muito além de simplesmente dançar, mas sim uma maneira de aprendermos a lidar com as mais diferentes culturas e costumes, coisa que muita gente, infelizmente, não sabe, entretanto, acredito que muitas destas passaram a entende-las melhor depois das aulas (Relato via whatsapp - DC - Aluna F).

A mistura entre o ser biológico, social e emocional por meio da dança atribui a essa manifestação uma proximidade significativa com a construção da identidade. Laban (1978) aponta que os movimentos revelam ações, sentimentos e ideias, e desta forma, instituímos na pesquisa novas formas de desenvolvimento cultural e social.

\section{E as TICs com isso?}

No geral, a avaliação discente em relação à utilização das TICs como recursos pedagógicos foi bastante positiva, posto que, desfrutar de aparatos como o celular e o computador, além das 
redes sociais como facebook, instagram e whatsapp, até então, era algo pouco explorado por eles em espaço escolar. Sobre o assunto eles pontuaram que:

"Foi legal, por causa que, por exemplo, [...] para mostrar uma imagem para gente aqui teria que imprimir né? Então foi legal a senhora ter mandado para gente, [...] e interagir uns com os outros pelo celular" (Informação verbal - GF - Aluna 7).

"Foi muito louco, porque tá presente no nosso dia-a-dia e a gente absorve muito mais fácil" (Informação verbal - GF - Aluno 5).

"Isso, porque a gente já está acostumado com essas coisas de tecnologias, então é legal" (Informação verbal - GF - Aluna 2).

[...] porque a gente é muito ligado a facebook, whatsapp e essas coisas, então se você manda uma mensagem lá, rapidamente já estamos ligados [...] (Relato via whatsapp - DC - Aluna D).

Podemos observar nos relatos que há uma forte ligação entre os alunos e as tecnologias, o que pode ser um ponto favorável para a inserção dessas ferramentas em espaços educativos. Ferreira e Wagner (2012) realizaram uma investigação que corrobora esses dados, já que os autores identificaram, ao analisar o perfil tecnológico de alunos do EM (advindos de escolas pública e privada), que eles possuem grande proximidade com as TICs em seu cotidiano.

As TICs podem transformar atividades supostamente mais tradicionais, ampliando seus significados. Isso pôde ser identificado, por exemplo, quando propusemos a análise de uma imagem pelo celular ao invés do papel, uma troca que causou maior interatividade e interesse. Germano (2015) em seu estudo utilizando o celular nas aulas de EF, encontrou uma "ligação" quase que emocional entre os alunos e os seus aparelhos, e isso acaba refletido nas experiências.

Assim, entendemos que o impacto das TICs foi positivo, pois os alunos se sentiram à vontade em jogar, fotografar e pesquisar sobre dança, muitas vezes até de forma espontânea. No grupo focal foi unânime o desejo para que abríssemos mais espaços para o universo digital, uma vez que, particularmente na EF eles nunca haviam tido oportunidades parecidas, o que também já foi evidenciado em outros estudos (MOLINA; DEVÍS; PEIRÓ, 2008).

Dentro dos recursos tecnológicos que empregamos, as redes sociais assumiram um posto de destaque, principalmente pelas relações que os alunos possuíam com elas. As redes sociais digitais versam sobre os desdobramentos das relações humanas no campo virtual, tornando-se um desafio desconsiderá-las na vida moderna (AMANTE, 2014).

O facebook e o instagram, em particular, possuem recursos simples e atrativos, o que os tornam populares. Os convidativos layouts estimulam a falar sobre si mesmo (SANTAELLA, 2013) 
recebendo "avaliações" de seus pares, isto é, "curtidas". Logo, acontecimentos que antes pertenciam ao universo particular agora são "espetacularizados".

Especificamente em nossa investigação, construímos no facebook dois grupos secretos, um para o curso de Informática e outro para o de Química. A proposta foi utilizar as redes sociais com propósitos educativos, fugindo do uso que eles já mantinham. Desenvolvemos pesquisas no facebook e no instagram, além do acesso a vídeos, imagens e comunidades para conhecer mais cada uma das danças. Ademais, os estudantes atuaram também como produtores de conteúdo postando nas redes algumas das experiências de aula.

Confrontar as expectativas pessoais dos alunos, seus preconceitos e concepções sobre as danças populares com saberes encontrados nas redes sociais possibilitou ainda reflexões sobre a discriminação que ocorre com as práticas da cultura popular, e, em especial com aquelas de matriz africana. Os relatos fortaleceram a importância de uma escola democrática e contrária a toda e qualquer forma de preconceito:

Foi muito interessante aprender cada cultura dos povos de antigamente, e que eram formas de "sobreviver" nas épocas difíceis! Que cada movimento tem seu significado e que não é à toa que tudo isso existe hoje! E isso é muito legal, porque muita gente despreza por hoje em dia não existir mais a escravidão, por exemplo (Relato via whatsapp - DC - Aluna D).

Foi uma ótima experiência, eu particularmente não gosto muito de dançar, mas foi muito bom aprender essas danças, e o mais importante conhecer novas culturas e respeitá-las (Relato via whatsapp - DC - Aluno G).

Essas experiências salientam o quanto as TICs podem ser aliadas no processo de aprendizagem, principalmente para os professores que possuem dificuldades em tratar atitudes e valores no contexto das práticas corporais. São vídeos, textos, páginas de projetos, enfim, um universo de possibilidades que podem enriquecer as aulas de EF.

Contudo, nas propostas orientadas fora do horário regular, a participação dos alunos pelo facebook não foi tão expressiva, o que evidenciou uma limitação da pesquisa. Tal situação também foi encontrada por Milani (2015) que, ao desenvolver uma investigação na disciplina de EF sobre gênero, identificou pouca participação nessa rede social. A autora levantou algumas hipóteses para explicar o baixo acesso, e dentre eles, demarcou o uso do facebook como ambiente de lazer. Carvalho (2012) complementa que de fato é muito difícil para os estudantes compreenderem sentidos pedagógicos em um espaço voltado principalmente ao entretenimento e a sociabilização, o que requer um trabalho contínuo de desconstrução. 
Do ponto de vista dos alunos, a plataforma dá um pouco mais de trabalho em relação ao whatsapp por exemplo, já que, nesse último a conexão é automática. O Aluno C também pontuou que o celular recebe notificações do whatsapp em tempo real, o que facilita o acesso:

A minha opinião é que [...] é muito mais rápido e fácil falar com todos pelo whatsapp e pelo facebook, se fossemos ficar sabendo das coisas pelo e-mail seria mais complicado, porque nem todo mundo mexe no e-mail, pois a maioria só usa pra pegar matéria, já no whatsapp quase todos utilizam $100 \%$ do dia (Relato via whatsapp - DC - Aluna K).

Nesse escopo, como apontam Bottentuit Junior et al., (2016) talvez essa seja a razão que coloque o whatsapp em posição de vantagem, pois há maior dinamismo e praticidade de acesso, elementos significativos para os jovens na atualidade. Bottentuit Junior et al. (2016) fizeram um levantamento sobre os estudos que têm empregado o aplicativo com finalidades educativas e identificaram uma intensificação nos últimos anos. Áreas como a História (LOPES; VAZ, 2016), Língua Portuguesa (SOMBRA SILVA, 2016), Matemática (BONA; PARAVISI, 2016), Química (ALMEIDA, 2015) entre outras, utilizaram o whatsapp para discussões, exercícios e outras atividades de apoio à aprendizagem.

Especificamente em nossa pesquisa, criamos grupos com cada uma das turmas participantes (4) e propusemos tarefas como análise de imagens e vídeos, troca de reflexões sobre as vestimentas, contexto histórico, passos básicos, além da produção e compartilhamento de conteúdo autoral. Estabelecemos naquele espaço regras de conduta que deveriam se aliar com a proposta da disciplina, de forma que prezaríamos pelo respeito e autonomia. Assim, foi possível criar um ambiente interativo que funcionou como oportunidades extras de aprendizagem, promovendo inclusive, o envolvimento dos alunos mais tímidos.

Nossos dados corroboram experiências encontradas em outros estudos sobre o envolvimento dos alunos em propostas que envolvem as tecnologias (JUSTO et al., 2015; GERMANO, 2015; LOPES; VAZ, 2016; SOMBRA SILVA, 2016; BONA; PARAVISI, 2016). O fato é que o mundo virtual abriu possibilidades para que eles manifestassem os seus sentimentos, opiniões e dúvidas sobre os conteúdos, criando maiores oportunidades formativas.

Eu acho ótimo, estabelece uma relação de proximidade entre o professor e aluno, já que é mais uma ferramenta de comunicação. O whatsapp é um meio que todos nós usamos com frequência para fazer tudo hoje em dia, nada mais justo que isso também sirva para tirar dúvidas, retomar avisos da sala de aula, entre várias outras coisas [...] (Relato via whatsapp - DC - Aluna H).

[...] utilizar o whatsapp é um meio muito bom, porque como os jovens estão ligados cada vez mais a tecnologia ultimamente, utilizar o whatsapp como forma 
didática é muito interessante [...] você pode mandar as fotos que vamos usar nas aulas [...] (Relato via whatsapp - DC - Aluna D).

É uma ótima ferramenta [..] as dúvidas que temos podemos tirar com a senhora. E as imagens utilizadas na aula ficam melhor vista por aqui, porque impressa as vezes não fica tão boa! É um meio rápido e eficaz. [...] E informar também sobre as notícias que a educação vem sofrendo. [...] Todas as matérias deveriam ter (Relato via whatsapp - DC - Aluna J).

Comparando os dados obtidos no grupo focal e aqueles coletados no whatsapp (registrados no diário de campo), apesar das impressões gerais serem as mesmas, a maneira como os alunos se expressaram foi bem diferente. Enquanto no primeiro, expressões como "legal”, "divertido", “ajuda na aula", foram usadas com frequência, no segundo eles foram muito mais detalhistas. Isso não quer dizer que acreditamos na substituição das estratégias, mas sim, em sua diversificação. Como aponta Freitas (2010) aliar os ambientes virtuais e presenciais no processo de aprendizagem intensifica uma formação criativa e autônoma.

Foi possível, portanto, evidenciar a partir do trabalho com a dança, o potencial educativo das TICs nas aulas de EF no Ensino Médio. Estamos diante de alunos que sentem prazer em filmar, fotografar, postar e compartilhar, e a apropriação desses recursos como princípios pedagógicos pode ser melhor explorada pela escola como um todo. Cabe salientar que trabalhar com tecnologias também significa lidar com a incerteza, pois ao longo do processo enfrentamos instabilidade na rede, indisponibilidade de laboratório de informática, divisão dos recursos entre os alunos, pois nem todos tinham acesso, entre outros fatores que limitaram algumas ações.

Por fim, compreendemos as TICs como um recurso didático a mais na sala de aula, ou seja, que possui ferramentas dinâmicas e interativas que podem auxiliar o professor. Isso significa que apesar dos seus benefícios, não podemos analisa-las sob um viés maniqueísta tratando-as como "solução" para os problemas da educação, mais sim, como uma possível aliada do processo educacional. Ademais, salientamos que recursos tecnológicos ainda são escassos em muitos lugares do país, e que é preciso um investimento maciço no acesso e na formação digital para que essas oportunidades possam ser compartilhadas em outros contextos.

\section{CONSIDERAÇÕES FINAIS}

Frente ao nosso objetivo de avaliar uma experiência com a dança no Ensino Médio utilizando as Tecnologias da Informação e Comunicação como recurso pedagógico, podemos salientar que foi possível trazer dados relevantes. Ademais, pudemos defender politicamente a 
relevância da dança na escola como um saber cultural contextualizado e que precisa ser garantido, já que muitas vezes ela ainda pouco aparece.

Analisando com maior proximidade, identificamos que as danças propostas na pesquisa foram aquelas que de fato compõem a cultura local, visto que estão presentes nas festas de diferentes naturezas, nos núcleos familiares, nos espaços de lazer e nas associações culturais. Tal indicativo direciona para a escola um acervo de práticas que precisam ser reconhecidas e preservadas como saberes curriculares, e que, portanto, precisam ser logrados como conteúdos.

Produzimos um material didático com os objetivos oferecidos pela segunda versão da BNCC para o conteúdo dança, considerando também suas orientações de compreender o Ensino Médio como uma etapa mais autônoma, o que colocou a comunidade escolar como parte do processo. Diante desse encaminhamento, apresentamos nossa pesquisa nas reuniões pedagógicas da escola, a fim de decidir coletivamente alguns encaminhamentos adotados e integrar a proposta da escola. Com isso, as manifestações elencadas foram o maculelê, as cirandas paulistas, o samba de lenço e o batuque de umbigada. Essas práticas foram compreendidas como relevantes dentro do tema interdisciplinar "Cultura e Identidades locais" proposto durante as reuniões coletivas da escola.

As falas dos estudantes ratificam o distanciamento que a dança ainda possui da escola, e evidenciam a relevância do nosso estudo ao tentar contribuir com a desconstrução desse panorama, ao menos em nossa realidade. Construímos experiências prazerosas com as danças populares e muito diferentes do que a maioria já havia vivenciado em outros espaços educativos. Implementamos um método de ensino que valorizou não só os saberes dos alunos mas também ferramentas do seu cotidiano, isto é, as tecnologias.

As TICs ressignificaram o ambiente de aprendizagem e aproximaram a vida dos estudantes da instituição escolar, o que foi possível constatar não só com a observação das aulas, mas também nas falas e nos registros do diário de campo. Os jovens possuem uma relação muito sólida com as tecnologias, até mesmo afetiva. Elas são rápidas, modernas, cada vez mais acessíveis e cativam pela diversidade de possibilidades.

Os grupos no whatsapp e facebook, as fotos, os vídeos e o instagram, possibilitaram que os conteúdos estivessem a um click dos alunos, o que foi motivador e até mesmo novo para alguns. Eles foram colocados como protagonistas da própria aprendizagem, recebendo estímulos para criar movimentos, para desenvolver pesquisas em tempo real, para registrar as experiências com os celulares, enfim, instauramos na EF momentos pedagógicos legítimos com o uso das TICs. 
Tivemos, portanto, uma extensão dos espaços de ensino e aprendizagem que, mesmo começando nas aulas, tinham continuidade nas redes sociais.

No geral, sinalizamos o estudo como relevante para área, pois pudemos avaliar experiências pedagógicas com o ensino da dança mediadas pelas TICs no EM, e dar subsídios para que outros professores possam se apropriar desses saberes por meio de um material didático. Entretanto, reconhecemos que há limitações, primeiro devido ao recorte, tendo em vista que o IFSP é uma instituição privilegiada em diversos sentidos; segundo em relação às tecnologias, pois foi possível não apenas utilizar os laboratórios da escola, como também os recursos individuais que a maioria dos alunos possuía; e por fim, o apoio contínuo da gestão e da comunidade interna que trabalhou de forma coletiva por meio do projeto interdisciplinar. É preciso acentuar também, o tempo e a quantidade de aulas utilizadas, uma vez que são necessárias mais experiências para dar continuidade a valorização da dança na EF, bem como a exploração de novas possibilidades pedagógicas com as tecnologias. Por fim, para replicar o estudo em outros contextos, são fundamentais boas condições de trabalho para o professor (materiais didáticos, infraestrutura, carga horária destinada a formação continuada, entre outros elementos) para que assim, a EF possa ser mais diversificada, crítica e significativa para toda a comunidade.

Como pontua Nóvoa (2006) nada substitui o bom professor, nem documentos curriculares, nem materiais didáticos muito menos as tecnologias. Pesquisas e projetos educacionais que visam melhorar o processo formativo em diversos sentidos, apesar de essenciais, não são a raiz do problema. Obviamente é extremamente importante que tais iniciativas continuem em prática enquanto não alcançamos as condições ideais nas instituições escolares, que continuarão sendo pouco efetivas diante da falta de investimentos na formação do professor.

\section{REFERÊNCIAS}

ALMEIDA, Gilvan Jorge de. Emprego do aplicativo whatsApp no ensino de química. 2015. 72 f. TCC (Graduação)

- Curso de Química, Instituto de Química, Universidade de Brasília, Brasília, 2015.

AMANTE, Lúcia. Facebook e novas sociabilidades contributos da investigação. In: PORTO, Cristiane; SANTOS, Edmea (Orgs). Facebook e Educação: publicar, curtir, compartilhar [online]. Campina Grande: EDUEPB, 2014. p. 21-46.

BETTI, Mauro. Mídias: aliadas ou inimigas da educação física escolar. Motriz, Rio Claro, v. 7, n. 2, p. 125-129, jul./dez. 2001.

BONA, Aline de; PARAVISI, Marcelo. O Whatsapp: um espaço de construção escolar e administrativa. Revista Thema, Pelotas, v. 13, n. 1, p. 15-23, 2016. 
BOTTENTUIT JUNIOR, João Batista; ALBUQUERQUE, Odla Cristianne Patriota. Whatsapp e suas aplicações na educação: uma revisão sistemática da Literatura. Revista EducaOnline, Rio de Janeiro, v. 10, n. 2, maio-ago. 2016, p. 67-87.

BRASIL. Base Nacional Comum Curricular. Brasília: MEC, UNDIME, CONSED, 2016.

BRASILEIRO, Lívia Tenório. Dança - Educação Física (in)tensas relações. 2009, 473f. Tese (Doutorado em Educação) - Faculdade de Educação, Universidade Estadual de Campinas, Campinas.

BRASILEIRO, Lívia Tenório. O conteúdo “dança” em aula de Educação Física: temos o que ensinar? Revista Pensar a Prática, Goiânia, v. 6, p. 45-48, 2002-2003.

CARVAlHO, Ana Amélia A. Mobile-Learning: rentabilizar os dispositivos móveis dos alunos para aprender. In: Ana Amélia A. Carvalho (Org.), Aprender na era digital - Jogos e mobile-learning. Santo Tirso: De Facto Editores, 2012. p. 149-163.

CASTELLS, Manuel. A sociedade em rede. São Paulo: Paz e Terra, 1999.

COLL, César; POZO, Juan Ignacio; SARABIA, Bernabé; VALLS, Enrich. Os conteúdos na reforma. Porto Alegre: Artmed, 2000.

DARIDO, Suraya Cristina. Educação física escolar: compartilhando experiências. São Paulo: Phorte, 2011.

DARIDO, Suraya Cristina. Educação física e temas transversais na escola. Campinas: Papirus, 2012.

DARIDO, Suraya Cristina; RANGEL, Irene Conceição Andrade. Educação física na escola: implicações para a prática pedagógica. Rio de Janeiro: Guanabara Koogan, 2005.

DARIDO, Suraya Cristina; SOUZA JÚNIOR, Osmar Moreira. Para ensinar educação física: possibilidades de intervenção na escola. Campinas: Papirus, 2007.

DINIZ, Irlla Karla dos Santos. Blog educacional para o ensino de danças folclóricas a partir do currículo de educação física do estado de São Paulo. 2014. 214f. Dissertação (Mestrado em Desenvolvimento Humano e Tecnologias) - Instituto de Biociências, Universidade Estadual Paulista, Rio Claro, 2014.

DINIZ, Irlla Karla dos Santos; DARIDO, Suraya Cristina. Análise do conteúdo dança nas propostas curriculares estaduais de educação física do Brasil. Revista da Educação Física - UEM, Maringá, v. 26, n. 3, p. 353-365, 3. trim. 2015 .

DINIZ, Irlla Karla dos Santos; DARIDO, Suraya Cristina. O que ensinar sobre dança no ensino médio? Revista Motrivivência, Florianópolis, v. 31, p. 01-23, 2019.

EHRENBERG, Mônica Caldas. A dança como conhecimento a ser tratado pela educação física escolar: aproximações entre formação e atuação profissional. 2003. 153f. Dissertação (Mestrado em Educação Física) Faculdade de Educação Física, Universidade Estadual de Campinas, Campinas, 2003.

ELLIOT, John. EI cambio educativo desde la investigación-acción. Madrid: Morata, 1993.

FERREIRA, Aline Fernanda. Os jogos digitais como apoio pedagógico nas aulas de educação física escolar pautadas no currículo do Estado de São Paulo. 2014. 127 f. Dissertação - (Mestrado) - Universidade Estadual Paulista, Instituto de Biociências de Rio Claro, 2014. Disponível em: http://hdl.handle.net/11449/108686. Acesso em: 20 nov. 2018.

FERREIRA, Vinícius H.; WAGNER, Paulo R. A tecnologia na escola: analisando o perfil tecnológico do aluno de Ensino Médio. In: Simpósio Brasileiro de Informática na Educação - SBIE, n. 23, 2012, Rio de Janeiro. Anais... 2012. p. $1-5$. 
FREITAS, Maria Tereza. Letramento digital e formação de professores. Educação em Revista, Belo Horizonte, v. 26, n. 3, p. 335-352, dez. 2010. Disponível em: http://www.scielo.br/pdf/edur/v26n3/v26n3a17.pdf. Acesso em: 07 dez. 2016.

GARAUDY, Roger. Dançar a vida. Editora Nova Fronteira. Rio de Janeiro: 1980.

GATTI, Bernadete Angelina. Grupo focal na pesquisa em ciências sociais e humanas. Brasília: Líber Livro, 2005.

GERMANO, Vitor Abdias Cabót. Educação física escolar e currículo do estado de São Paulo: possibilidades dos usos do celular como recurso pedagógico no ensino do hip hop e street dance. 2015. 160f. Dissertação (Mestrado em Desenvolvimento Humano e Tecnologias) - Instituto de Biociências, Universidade Estadual Paulista, Rio Claro, 2015.

GIL, Antônio Carlos. Como elaborar projetos de pesquisa. 4. ed. São Paulo: Atlas, 2008.

GIL, Antônio Carlos Métodos e técnicas em pesquisa social. 5. ed. São Paulo: Atlas, 1999.

GONZÁLEZ, Fernando Jaime; FENSTERSEIFER, Paulo Evaldo. Entre o "não mais" e o "ainda não": pensando saídas do não-lugar da EF escolar I. Caderno de Formação RBCE, Florianópolis, v. 1, p. 9-24, 2009. Disponível em: http://www.rbceonline.org.br/revista/index.php/cadernos/article/view/929/539. Acesso em: 20 dez. 2018.

GOZZI, Márcia Cândida Teixeira; RUETE, Helena Maria. Identificando estilos de ensino em aulas de educação física em segmentos não escolares. Revista Mackenzie de Educação Física e Esporte, Ano 5, n. 1, p. 117-134, 2006.

JUSTO, Maria das Dores; CABRAL, Juliana da Silva; ARAÚJO, Andreia Rafael de; BARBOSA, Janaína da Costa. Multiletramentos na escola: interface fílmico com a literatura e o whatsapp. In: Congresso Nacional de Educação CONEDU, n. 2, 2015, Campina Grande, PB. Anais... 2015, p. 1-10.

KENSKI, Vani Moreira. Educação e tecnologias: o novo ritmo da informação. 6. ed. Campinas, SP: Papirus, 2010.

LABAN, Rudolf. Domínio do movimento. São Paulo: Summus, 1978.

LOPES, Cristiano Gomes. VAZ, Braz Batista. O ensino de história na palma da mão: o whatsapp como ferramenta pedagógica para além da sala de aula. In: Simpósio Internacional de Educação a distância - SIED e Encontro de pesquisadores em Educação a distância - EnPED, n. 3, 2016, São Carlos, SP. Anais... 2016, p.1-14.

MAANEN, Jonh Van. Reclaiming qualitative methods for organizational research: a preface. Administrative Quaterly Science, v. 24, n. 4, p. 520-526, dez. 1979.

MASETTO, Marcos Tarciso. Metodologias ativas e o processo de aprendizagem na perspectiva da inovação. In: Congresso Internacional PBL, n.1. São Paulo, SP. Anais..., São Paulo, 2010.

MILANI, Amanda Gabriele. Gênero nas aulas de educação física: diálogos possíveis com os conteúdos do currículo do estado de São Paulo e o facebook. 2015. 174f. Dissertação (Mestrado em Desenvolvimento Humano e Tecnologias) - Instituto de Biociências, Universidade Estadual Paulista, Rio Claro, 2015.

MINAYO, Maria Cecília de Souza. O desafio do conhecimento: pesquisa qualitativa em saúde. 10. ed. São Paulo: Hucitec, 2000.

MOLINA, Juan Pérez; DEVÍS, José; PEIRÓ, Carmem J. Materiales curriculares: clasificación y uso en educación física. Revista de Medios y Educación, Sevilla, n. 33 Jul. 2008, p.183 - 197.

NANNI, Dionísia. Dança-educação: Pré-escola à Universidade. Rio de Janeiro: Editora Sprint, 1995.

NÓVOA, Antônio. Nada substitui o bom professor. Palestra proferida no SINPRO-SP. São Paulo, 2006.

PERRENOUD, Philippe. Práticas pedagógicas, profissão docente e formação: perspectivas sociológicas. Lisboa: Dom Quixote, 1997. 
POZO, Juan Ignacio; ECHEVERRÍA, Maria Del Puy Pérez. Aprender a resolver problemas e resolver problemas para aprender. Porto Alegre: Artes Médicas, 1998.

PRENSKI, Marc. Digital game-based learning. New York: McGraw-Hill, 2001.

SANTAELLA, Lucia. Comunicação ubíqua: Repercussões na cultura e na Educação. São Paulo: Paulus, 2013.

SANTOSO, Viviane Cesar Caldeira Lombardi; FREITAS, Alessandro de. A dança no ensino médio: contextualizando o aprendizado. EF Deportes, Buenos Aires, ano 15, n. 143, abr. 2010. Disponível em:

http://www.efdeportes.com/efd143/adancanoensinomediocontextualizando.htm. Acesso em: 02 set. 2015.

SBORQUIA, Silvia Pavesi; GALLARDO, Jorge Sergio Perez. As danças na mídia e as danças na escola. Revista Brasileira de Ciência e Esporte. Campinas, v. 23, n. 2, p. 105-118, jan. 2002.

SCARPATO, Marta Thiago. Dança educativa: um fato em escolas de São Paulo. Cadernos Cedes, Campinas, Ano XXI, n. 53, abr. 2001.

SCARPATO, Marta Thiago. Os procedimentos de ensino fazem a aula acontecer. São Paulo: Avercamp, 2004.

SCHIAVON, Laurita Marconi. O projeto crescendo com a ginástica: uma possibilidade na escola. 2003. $203 \mathrm{f}$. Dissertação (Mestrado em Educação Física). Faculdade de Educação Física, Universidade Estadual de Campinas, Campinas, 2003.

SILVEIRA, Guilherme Carvalho Franco da; PINTO, Joelcio Fernandes. Educação física na perspectiva da cultura corporal: uma proposta pedagógica. Rev. Brasileira de Ciência do Esporte, São Paulo, v. 22, n. 3, p. 137-150, maio 2001 .

SOMBRA SILVA, Jeanny Meiry. Práticas linguagem no whatsapp: perspectivas de sua utilização em sala de aula. Revista Travessias, Cascavel, v. 10, n.1, p. 434-448, 2016.

THIOLLENT, Michel. Metodologia da pesquisa ação. 6. ed. São Paulo: Cortez, 1994.

THOMAS, Jerry R.; NELSON, Jack. K.; SILVERMAN, Stephen. J. Métodos de pesquisa em atividade física. 5. ed. Porto Alegre: Artmed, 2007.

TRIPP, David. Pesquisa-ação: uma introdução metodológica. Educação e Pesquisa, v. 31, n. 3, p. 443-466, set/dez. 2005.

\section{NOTAS DE AUTOR}

\section{AGRADECIMENTOS}

Ao IFSP - Capivari, a UNESP - Rio Claro e a CAPES pelo incentivo a ciência e apoio sob a forma de bolsa de pesquisa.

CONTRIBUIÇÃO DE AUTORIA - Não se aplica.

\section{FINANCIAMENTO}

CAPES - Bolsa de Doutorado para autora principal do projeto de pesquisa (durante o período de sete meses - interrompida por aprovação em concurso público)

CONSENTIMENTO DE USO DE IMAGEM - Não se aplica. 


\section{APROVAÇÃO DE COMITÊ DE ÉTICA EM PESQUISA}

A pesquisa foi aprovada pelo Comitê de Ética em Pesquisa do Instituto de Biociências - UNESP Rio Claro. CAAE: 45603015.5.0000.5465; Parecer: 1.210.309.

CONFLITO DE INTERESSES - Não se aplica.

\section{LICENÇA DE USO}

Os autores cedem à Motrivivência - ISSN 2175-8042 os direitos exclusivos de primeira publicação, com o trabalho simultaneamente licenciado sob a Licença Creative Commons Attribution Non-Comercial ShareAlike (CC BY-NC SA) 4.0 International. Esta licença permite que terceiros remixem, adaptem e criem a partir do trabalho publicado, desde que para fins não comerciais, atribuindo o devido crédito de autoria e publicação inicial neste periódico desde que adotem a mesma licença, compartilhar igual. Os autores têm autorização para assumir contratos adicionais separadamente, para distribuição não exclusiva da versão do trabalho publicada neste periódico (ex.: publicar em repositório institucional, em site pessoal, publicar uma tradução, ou como capítulo de livro), com reconhecimento de autoria e publicação inicial neste periódico, desde que para fins não comerciais e compartilhar com a mesma licença.

\section{PUBLISHER}

Universidade Federal de Santa Catarina. Programa de Pós-Graduação em Educação Física. LaboMídia - Laboratório e Observatório da Mídia Esportiva. Publicado no Portal de Periódicos UFSC. As ideias expressadas neste artigo são de responsabilidade de seus autores, não representando, necessariamente, a opinião dos editores ou da universidade.

\section{EDITORES}

Mauricio Roberto da Silva, Giovani De Lorenzi Pires, Rogério Santos Pereira.

\section{EDITOR DE SEÇÃO}

Juliana Silveira.

\section{REVISÃO DO MANUSCRITO E METADADOS}

João Caetano Prates Rocha; Keli Barreto.

\section{HISTÓRICO}

Recebido em: 19 de março de 2021.

Aprovado em: 16 de junho de 2021. 